\title{
Morphometric Analysis of the Effects of Manuka Honey on Vasospastic Femoral Arteries in Rats: An Experimental Study
}

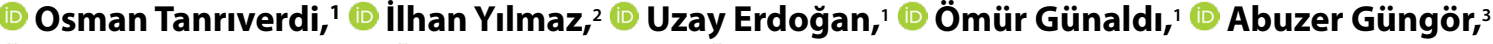 \\ (D) Hüseyin Utku Adilay, ${ }^{4}$ (I) Ayça Arslanhan, ${ }^{5}$ (D) Bekir Tuğcu'
}

'Departments of Neurosurgery and Psychiatry, Bakırköy Dr. Mazhar Osman Mental Health and Neurological Diseases Training and Research Hospital, Istanbul, Turkey

${ }^{2}$ Department of Neurosurgery, University of Health Sciences, Sisli Hamidiye Etfal Training and Research Hospital, Istanbul, Turkey ${ }^{3}$ Department of Neurosurgery, Acibadem University, Medical Faculty, Istanbul, Turkey

${ }^{4}$ Department of Neurosurgery, Balikesir University, Medical Faculty, Balikesir, Turkey

${ }^{5}$ Department of Neurosurgery, Marmara University, Institute of Neurological Science, Istanbul, Turkey

\begin{abstract}
Objectives: The aim of this study was to determine if Manuka honey, a potent anti-inflammatory and antioxidant agent, had any effect on the development of vasospasm in an experimental subarachnoidal hemorrhage model constructed in rat femoral arteries.

Methods: Twenty-four Wistar Albino strain rats were divided into 3 groups: Group 1 was the control group ( $n=8)$, Group 2 was the vasospasm group $(n=8)$, and group 3 was the treatment group $(n=8)$. The wall thickness $(W)$ of the femoral arteries and the luminal diameter $(\mathrm{L})$ were measured using morphometric methods. The data were analyzed with statistical software. The Mann-Whitney U-test was used to compare independent groups and Bonferroni post hoc analysis was used for multiple comparison tests. Significance for all of the results was established at $p<0.05$.

Results: A statistically significant intergroup difference was detected in the mean $L$ and $W(p<0.001, p=0.001$, respectively). The mean $L$ value in Group 2 was statistically significantly less than that of Groups 1 and 3, while the mean W value was significantly greater ( $p<0.001$ for all). However, no statistically significant difference was detected between Groups 1 and 3 with respect to the mean $L$ and $W$ values ( $p=0.064, p=0.954$, respectively).

Conclusion: Manuka honey exerts an antioxidant and anti-inflammatory effect via inhibition of inflammatory cytokines, including plasma tumor necrosis factor alpha, interleukin (IL)-1 beta, IL-6, and the lipid peroxidation level. This study statistically demonstrated that the anti-inflammatory and antioxidant properties of Manuka honey successfully inhibited the development of vasospasm in an experimentally induced vasospasm model in the femoral arteries of rats.

Keywords: Antioxidant; anti-inflammatory; manuka honey; subarachnoidal hemorrhage; vasospasm.

Please cite this article as "Tanrıverdi O, Yılmaz I, Erdoğan U, Günaldı Ö, Güngör A, Adilay HU, Arslanhan A, Tuğcu B. Morphometric Analysis of the Effects of Manuka Honey on Vasospastic Femoral Arteries in Rats: An Experimental Study. Med Bull Sisli Etfal Hosp 2018;52(4)268-273.
\end{abstract}

C erebral vasospasm (CV) is one of the most serious causes of long-term morbidity and mortality after subarachnoidal haemorrhage $(\mathrm{SAH}) .^{[1,2]}$ Large-scale investigations have been performed on this topic, but the etiology and pathogenesis of $\mathrm{CV}$ remain unclear. An effective medical treatment modality has yet to be developed. ${ }^{[1]}$ Vasocon- striction theories suggest a role for free lipid peroxidation radicals in the etiopathogenesis of CV. Honey possesses strong antioxidant and anti-inflammatory properties, and it has been adopted for clinical use in some fields. Several studies have evaluated effects of various substances with antioxidant properties on the development of $\mathrm{CV}$ in vivo

Address for correspondence: Osman Tanrıverdi, MD. Bakırköy Dr. Mazhar Osman Ruh Sağlığı ve Nörolojik Hastalıklar Eğitim ve Araştırma Hastanesi, Nöroşirürji ve Psikiyatri Anabilim Dalı, Istanbul, Turkey

Phone: +90 5052964052 E-mail: osmantanriverdi74@gmail.com

Submitted Date: May 22, 2018 Accepted Date: June 27, 2018 Available Online Date: December 28, 2018

${ }^{\circ}$ Copyright 2018 by The Medical Bulletin of Sisli Etfal Hospital - Available online at www.sislietfaltip.org This is an open access article under the CC BY-NC-ND license (http://creativecommons.org/licenses/by-nc/4.0/). 
and in vitro; however, studies using only honey have not been performed. ${ }^{[3]}$ In this study, we investigated the effectiveness of honey (if any) on the inhibition of vasospasm in rat femoral arteries using an experimentally induced SAH model. We also assessed the in vivo applicability of honey on vessel walls in living creatures.

\section{Methods}

This experimental study was performed with the approval of the Ethics Committee of Çukurova University Medical Sciences Experimental Research and Application Center. Surgeries were performed at the Experimental Animals Research Laboratory of Marmara University Institute of Neurological Sciences, whereas histopathologic and morphometric studies were performed at the Bakırköy Dr. Sadi Konuk Training and Research Hospital, Department of Pathology.

In our study, 24 female Wistar Albino strain rats weighing 220-250 $\mathrm{g}$ were used. The femoral artery vasospasm model described by Okada et al. ${ }^{[4]}$ was employed. The rats were divided into three groups: group 1 (control group, $n=8$ ), group 2 (vasospasm group, $\mathrm{n}=8$ ), and group 3 (treatment group, $\mathrm{n}=8$ ).

The rats were anesthetized with intraperitoneal administration of $50 \mathrm{mg} / \mathrm{kg}$ ketamine $\mathrm{HCl}$ (Ketalar flacon, $50 \mathrm{mg} /$ $\mathrm{ml}$, Pfizer), and they were laid supine on cork blocks. Inguinal regions of the rats were shaved and disinfected with povidone-iodine (PVD-I) solution. Under the guidance of a surgical microscope, a 2 -cm long longitudinal skin incision was made, and the femoral neurovascular bundle was exposed. The femoral artery was carefully dissected away from the femoral vein and nerve bundle. A silastic sheath was wrapped and sutured around a 1-1.5-cm long segment of the femoral artery. Autologous cardiac blood samples from the rats were used as whole blood. For rats in groups 2 and 3, 0.1 cc of intracardiac arterial blood was drawn using an insulin injector through a percutaneous route, and it was then injected into the silastic sheath to create a peripheral vasospasm model. Afterward, $0.1 \mathrm{ml}$ honey was applied locally to the silastic sheath in group 3; and $0.1 \mathrm{ml}$ of $0.9 \%$ physiologic saline was applied locally in group 1.

The rats were kept at normal room temperature for 7 days. Each rat was housed in a separate cage, and was fed with rat food pellets.

At the end of the seventh day, the rats were sedated with percutaneously delivered intraperitoneal $2 \mathrm{mg} / \mathrm{kg}$ ketamine, and they were fixed on cork blocks in a supine position. The silastic sheath around femoral artery was approached and opened through the previous incision to reveal the femoral artery. The presence of the femoral artery inside the silastic sheath was confirmed in all rats. The skin over the sternum was shaved. Following sterilization with the PVD-I solution, the sternum was dissected away from the ribs, and the thorax was explored. The pericardium was opened, and a green-tipped injection needle was placed in the left ventricle. A serum set was mounted on the tip of a catheter (the serum set was hung $10 \mathrm{~cm}$ above the level of the heart to maintain physiologic arterial blood pressure), and a mixture of $100 \mathrm{ml} 0.03 \mathrm{M}$ phosphate buffer, $200 \mathrm{ml}$ $4 \%$ paraformaldehyde, and $1 \%$ glutaraldehyde solution was delivered through the left ventricle. The delivered solution circulated through the vascular system, and infusion was maintained until clear fluid exited the previously opened right atrium.

In all groups, 1-1.5-cm long segments of the right femoral arteries were harvested for histopathological morphometric analysis. After these procedures, the rats were sacrificed by cervical dislocation.

Femoral artery specimens immersed in buffered $10 \%$ formaldehyde were cassetted and placed in a tissue maintenance device then treated with formaldehyde for fixation. The fixed tissues were dehydrated with graded alcohol, treated with xylene, and embedded in paraffin. At the end of this process, tissue specimens in paraffin were frozen as paraffin blocks. Five-micron-thick sections were cut using a microtome and deparaffinized by placing in an incubator at $60^{\circ} \mathrm{C}$ for $1 \mathrm{~h}$. Deparaffinization was performed thrice with xylene. The specimens were treated with graded alcohol for rehydration, and rinsed with water before staining with toluidine blue dye. The prepared slides were examined under a microscope at 100x, 200x, and 400x magnification, and they were photographed for morphometric analysis. Vascular wall thickness (W) and luminal diameters (L) were measured using the Image $J 1.34$ program and expressed as unit values. Measurements were made based on photos taken at $40 \times$ magnification. In morphometric analysis, vascular $L$ and $W$ of the groups were correlated, and the specimens were compared.

\section{Statistical Analysis}

Data were analyzed using the IBM Statistical Package for Social Sciences v15 (SPSS Inc., Chicago, IL, USA). The MannWhiney $U$ and Kruskal-Wallis tests were used to compare independent groups. The Bonferroni post hoc analysis was used for multiple comparison tests. The results for all items were assessed with a significance level of $p<0.05$.

\section{Results}

The resected femoral artery samples were examined under a surgical microscope. Various degrees of vasoconstriction, ranging from mild to severe, were observed in groups 2 and 3 , whereas such changes were not detected in group 1 (Table 1). 
Table 1. Comparison of arterial stenosis among groups 1, 2, and 3.

\begin{tabular}{cccc}
\hline & Mean \pm SD & Min-Max & Median \\
\hline L & & & \\
Group 1 & $1123.0 \pm 47.3$ & $1052-1190$ & 1110 \\
Group 2 & $412.9 \pm 82.0$ & $326-562$ & 393.5 \\
Group 3 & $1076.5 \pm 24.5$ & $1044-1112$ & 1079 \\
& & $<0.001$ & \\
W & & & \\
Group 1 & $103.4 \pm 7.2$ & $91-113$ & 105 \\
Group 2 & $174.0 \pm 29.2$ & $135-220$ & 165.25 \\
Group 3 & $104.5 \pm 6.1$ & $98-115$ & 103 \\
& & 0.001 & \\
Subgroup Analysis & & & \\
\hline & L & D & \\
& p & P & \\
\hline Group 1 vs. Group 2 & 0.001 & 0.001 & \\
Group 1 vs. Group 3 & 0.064 & 0.954 & \\
Group 2 vs. Group 3 & 0.001 & 0.001 & \\
\hline
\end{tabular}

Under microscopic examination, resected femoral arteries demonstrate arterial stenosis increasing in severity from group 2 (mild) to group 3 (severe). No changes were detected in group 1.

Statistically significant differences were detected between groups for mean values of $L$ and $W(p<0.001$ and $p=0.001$, respectively). Mean $L$ and $W$ of group 2 were significantly lower and higher, respectively, than those of groups 1 and 3 (for all, $\mathrm{p}<0.001$ ). A statistically significant difference was not detected between mean $L$ and $W$ values of groups 1 and 3 ( $p=0.064$ and $p=0.954$, respectively) (Fig. 1).

\section{Histopathological Changes}

Femoral artery sections from all groups were examined under a light microscope. In group 1, arteries had a thin and smooth endothelium, with thin and uncurled internal elastic lamina and concentrically arrayed smooth muscle cells. Stenotic lumens and thickened vascular walls were not observed (Fig. 2). In group 2, markedly narrowed arterial lumens and predominantly thickened vascular walls were observed, coupled with impairment of endothelial integrity, curled internal elastic lamina, and vacuolization of the muscular layer (Fig. 3). In group 3, the arterial structure resembled that of group 1. In other words, arteries in group 3 had an outer thin and smooth endothelial layer, with thin and patchy areas containing mildly curled internal elastic lamina and concentrically arrayed smooth muscle cells (Fig. 4).

\section{Discussion}

In $\mathrm{CV}$, pathological vasoconstriction caused by the accumulation of blood and blood products in the cerebral cisterns leads to decreased perfusion in distal segments of the involved artery. ${ }^{[5,6]}$ Experimental SAH models have been

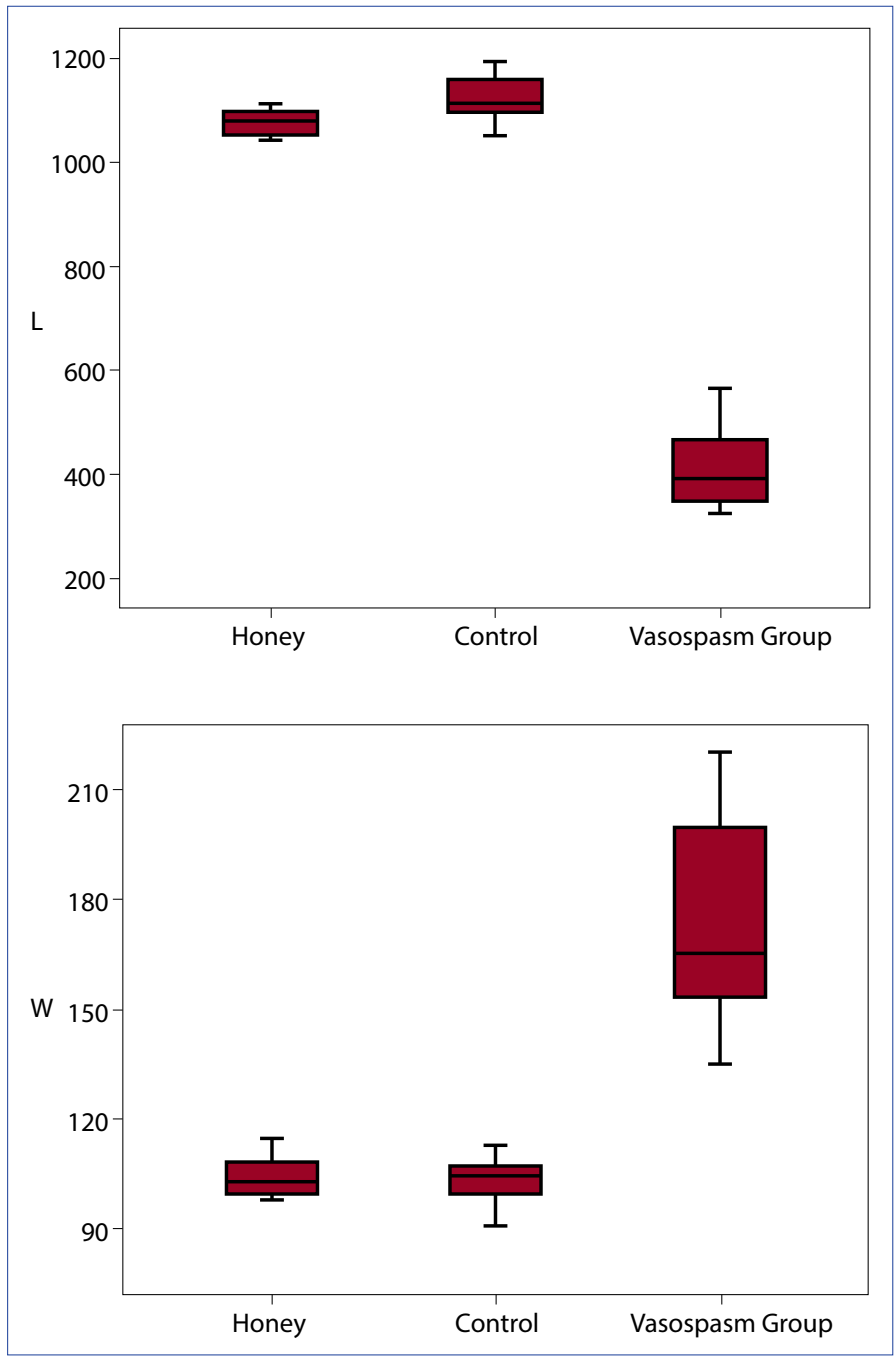

Figure 1. Mean $L$ and $W$ of the groups were statistically significantly different $(p<0.001$ and $p=0.001$, respectively). Mean $L$ of group 2 was statistically significantly lower than that of groups 1 and 3. However, mean W of group 2 was significantly higher (for all, $\mathrm{p}<0.001$ ). A statistically significant difference in mean $L$ and $W$ was not detected between groups 1 and 3 ( $p=0.064$ and $p=0.954$, respectively).

constructed since the 1960s, and numerous studies have been performed to understand the etiology of vasospasm. In addition, many drugs have been evaluated to prevent and treat vasospasm. Vasospasm has been attributed to many factors including blood degradation products, inflammation, and oxidants. ${ }^{[7,8]}$

Examination of cerebral arteries after experimental SAH under light and electron microscopes revealed structural changes such as thickening of the vessel wall, decreased $L$, thickening of the internal elastic lamina, disruption of the structure and integrity of endothelial cells, migration of myointimal cells into the vacuoles of smooth muscle cells and intima, perivascular axon loss, and periadventitial inflammation. ${ }^{[9]}$ 


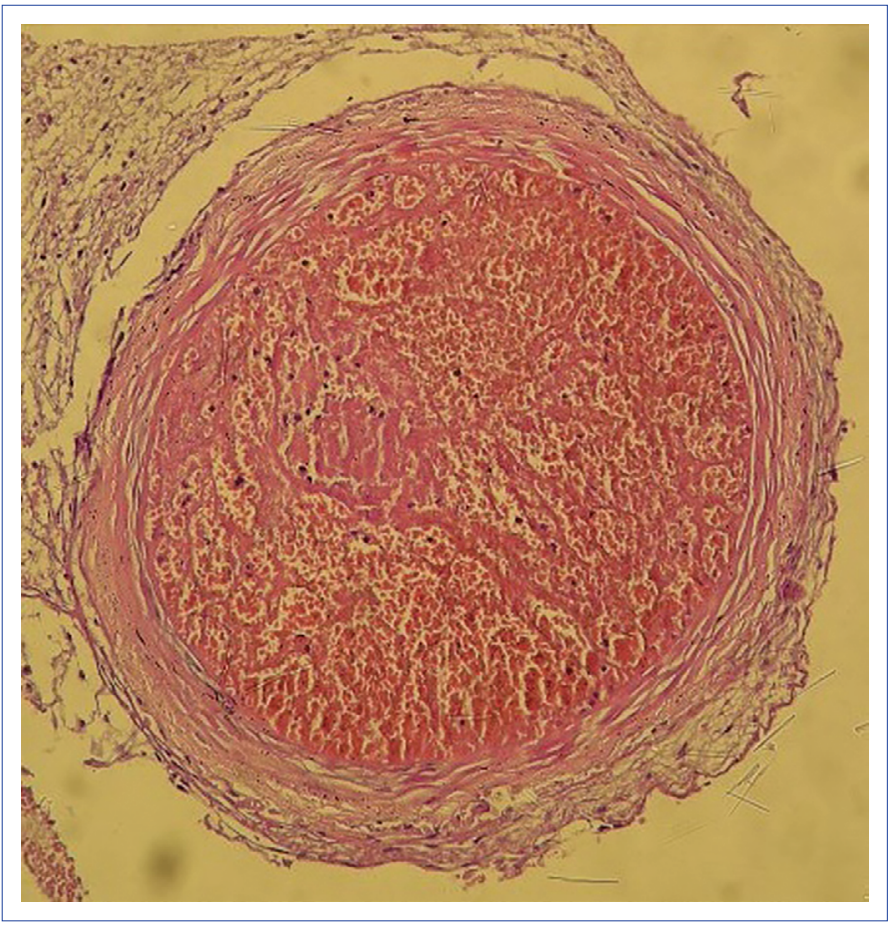

Figure 2. Group 1 (control group): Thin and smooth endothelium, thin and uncurled internal elastic lamina, and concentrically arrayed smooth muscle cells were observed in the arteries, while stenotic arterial lumen and thickened arterial walls were not observed.

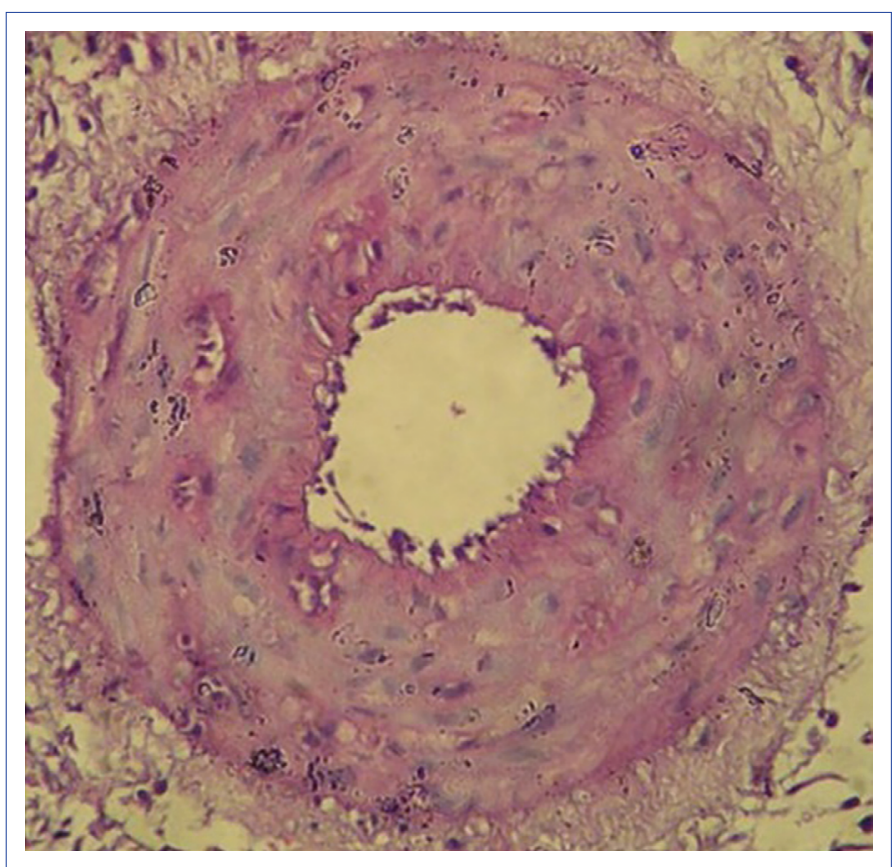

Figure 3. Group 2 (vasospasm group): Marked narrowing of the arterial lumen, impairment of endothelial integrity, curling of internal elastic lamina, and vacuolization of the muscular layer were observed.

Peterson et al. ${ }^{[10]}$ reported severe inflammation in the vasospastic vessel wall following SAH. They also reported that this inflammation induced vasospasm as well as other

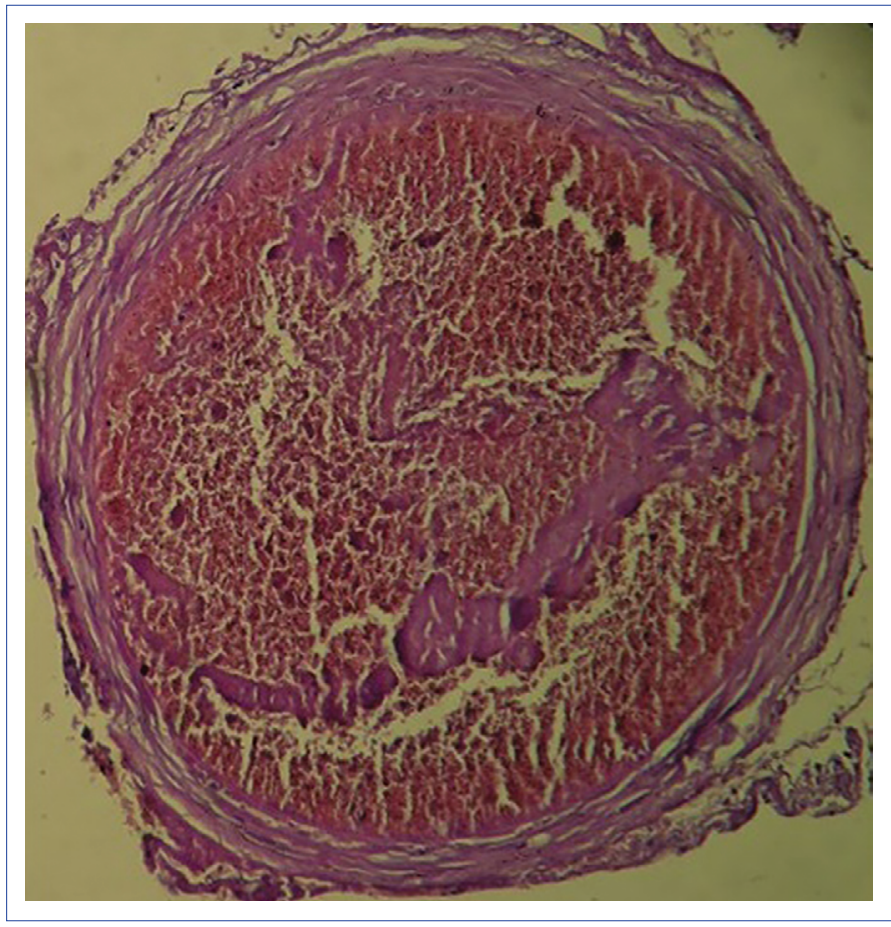

Figure 4. Group 3 (treatment group): Arteries are surrounded by thin and smooth outer endothelial layer similar to that observed in group 1. Patchy areas of slightly curved internal elastic lamina with concentric smooth muscle cells were observed.

etiologic factors. They added that prevention of inflammation may limit the development of vasospasm. Handa et al. explored the inflammatory reaction in the arterial wall and its time of onset in CV following SAH. They detected infiltration of inflammatory cells in the spastic arterial wall at the end of the first week, with myonecrosis and intimal deterioration occurring within the second week. ${ }^{[11]}$

Fassbender et al. reported that proinflammatory cytokines, IL- $\beta$, IL- 6 , and TNF- $\alpha$, trigger an inflammatory phase, leading to tissue damage. They also identified inflammatory response as the main cause of vasospasm in patients with $\mathrm{SAH}$, stating that anti-inflammatory and anti-cytokine treatment might prevent ischemic complications after SAH..$^{[12]}$ The results of a study by Lin et al. ${ }^{[12]}$ contributed to the rapidly growing evidence on the role of inflammatory response in the pathogenesis of CV following aneurysmal $\mathrm{SAH}$. This group identified vasospasm-preventive effects using antibodies against E-selectin, which may be involved in the pathogenesis of vasospasm.

It has been speculated that free radicals play a role in the development of CV. Some of the protective mechanisms developed by an organism against free radicals are aimed at inhibiting their formation and preventing their deleterious effects. Agents that exert these protective functions are called antioxidants. ${ }^{[13]}$ Antioxidants protect tissues and 
cells against oxidative injury, conferring protection against aging, tissue damage, and toxic agents. ${ }^{[14]}$

Honey comprises 180 different substances mainly including enzymes, followed by amino acids, gluconic acid, phenol compounds, lactones, minerals, and various vitamins. Honey also contains valuable minerals such as iron, copper, potassium, calcium, magnesium, phosphorus, silicium, aluminum, nickel, and cobalt. Discriminative characteristics of honey are determined by the nectar and many small components originating from the honey bee. ${ }^{[15,16]}$

Honey is effective in wound healing. It stimulates lymphocytic and phagocytic activities because of its anti-inflammatory properties. ${ }^{[17,18]}$ Honey can reduce inflammation and edema in wounds while simultaneously inducing epithelization. ${ }^{[19,20]}$

Manuka honey exerts antioxidant effects by inhibiting inflammatory cytokines, such as plasma TNFa, IL-1 $\beta$, and IL6 , as well as by reducing lipid peroxidation. ${ }^{[21]}$ Antioxidant characteristics of honey are derived from its components, which include polyphenols, such as flavonoids and phenolic acids; vitamins, such as thiamin, riboflavin, a-tocopherol, ascorbic acid, salicylic acid, sulfhydryl compounds and carotenoid derivatives; enzymes, such as glucosidase, catalase, and peroxidase; organic acids; amino acids; and proteins. ${ }^{[15,19,22,23]}$

This study was conducted under the hypothesis that Manuka honey exerts antioxidant effects by inhibiting plasma inflammatory cytokines, including plasma TNFa, IL$1 \beta$, and IL-6, as well as by reducing the level of peroxidation and the effects of oxidant substances, resulting in the reinforcement of the antioxidant defense mechanism and inhibition of vasospasm. However, the composition of honey and the relative proportion of its components demonstrate variations according to geographic conditions. Therefore, in our study, we used Manuka honey with its standardized content that is relatively rich in active enzymes and substances whose pharmaceutical forms have been approved by FDA for use in humans. The study was performed using the peripheral chronic vasospasm model developed by Okada et al. In addition, autologous arterial whole blood samples described by Okada et al..$^{[4]}$ were used.

Comparison of the vascular $W$ and $L$ of the control (group 1) and treatment (group 3) groups with those of the vasospasm group (group 2) showed significantly larger vascular lumen with significantly smaller vascular $W$ in groups 1 and 3 than that in group 2. Vascular W and L were significantly different between groups 1 and 2 . The incidence of vasospasm in group 3 was nearly equivalent to that in group 1 because of preventive effects of honey.

Our study demonstrated statistically significant inhibitory effects of Manuka honey on experimentally induced vasospasm. However, we could not determine whether these inhibitory effects could be attributed to the honey as a whole or to one or more of the components.

\section{Conclusion}

We demonstrated successful inhibition of vasospasm by honey using an experimentally induced vasospasm model created in femoral arteries of rats. However, effects of honey on cerebral vessels and the brain tissue have not been ascertained. Further experimental and clinical studies should be performed to confirm inhibitory effects of honey on post-SAH vasospasm.

\section{Disclosures}

Ethics Committee Approval: This experimental study was performed with the approval of the ethics committee of Çukurova University Medical Sciences Experimental Research and Application Center. 19.06.2012/20.

Peer-review: Externally peer-reviewed.

Conflict of Interest: The authors declare no conflict of interest.

Authorship contributions: Concept - O.T., Ö.G.; Design - O.T., I.Y.; Supervision - Ö.G., B.T.; Materials - A.A., U.E.; Data collection \&/or processing - A.A., H.U.A.; Analysis and/or interpretation O.T., A.G.; Literature search - U.E., H.U.A.; Writing - O.T., A.G.; Critical review - B.T., Ö.G.

Aknowledgement: We would like to thank Doç. Dr. Damlanur Sakız for the pathological examinations of this study.

\section{References}

1. Egemen N, Türker RK, Sanlidilek U, Zorlutuna A, Bilgiç S, Baskaya $M$, et al. The effect of intrathecal sodium nitroprusside on severe chronicvasospasm. Neurol Res 1993;15:31-5. [CrossRef]

2. Fassbender K, Hodapp B, Rossol S, Bertsch T, Schmeck J, Schütt $S$, et al. Inflammatory cytokines in subarachnoid haemorrhage: associationwith abnormal blood flow velocities in basal cerebral arteries. J Neurol Neurosurg Psychiatry 2001;70:534-7. [CrossRef]

3. Dina Jarjis R, Thomas Crewe B, Henrik Matzen S. Post-bariatric abdominoplasty resulting in wound infection and dehiscence-Conservative treatment with medical grade honey: A case report and review of literature. Int J Surg Case Rep 2016;20:1-3. [CrossRef]

4. Okada T, Harada T, Bark DH, Mayberg MR. A rat femoral artery model for vasospasm. Neurosurgery 1990;27:349-56. [CrossRef]

5. Anderson GB, Ashforth R, Steinke DE, Findlay JM. CT angiography for the detection of cerebral vasospasm in patientswith acute subarachnoid hemorrhage. AJNR Am J Neuroradiol 2000;21:1011-5.

6. Chehrazi BB, Giri S, Joy RM. Prostaglandins and vasoactive amines in cerebral vasospasm afteraneurysmal subarachnoid hemorrhage. Stroke 1989;20:217-24. [CrossRef]

7. Gumus E, Adilay U, Gunaldi O, Bayindir C, Kazanci B, Guclu B. The effect of copper on vasospastic femoral artery in rats. Turk Neuro- 
surg 2014;24:25-9.

8. Günaldi $O$, Tuğcu B, Cöllüoğlu B, Güçlü DG, Tanriverdi O, Akdemir $\mathrm{H}$, et al. Morphometric analysis of the influence of selenium over vasospastic femoral artery in rats. Acta Neurochir (Wien) 2010;152:855-60. [CrossRef]

9. Gules I, Satoh M, Clower BR, Nanda A, Zhang JH. Comparison of three rat models of cerebral vasospasm. Am J Physiol Heart Circ Physiol 2002;283:H2551-9. [CrossRef]

10. Peterson JW, Kwun BD, Hackett JD, Zervas NT. The role of inflammation in experimental cerebral vasospasm. J Neurosurg 1990;72:767-74. [CrossRef]

11. Handa $Y$, Kabuto M, Kobayashi $H$, Kawano $H$, Takeuchi $H$, Hayashi $M$. The correlation between immunological reaction in the arterial wall and the time course of the development of cerebral vasospasm in a primate model. Neurosurgery 1991;28:542-9. [CrossRef]

12. Lin $C L$, Dumont AS, Calisaneller T, Kwan AL, Hwong SL, Lee KS. Monoclonal antibody against $\mathrm{E}$ selectin attenuates subarachnoid hemorrhage-induced cerebral vasospasm. Surg Neurol 2005;64:201-5. [CrossRef]

13. Frei B. Reactive oxygen species and antioxidant vitamins: mechanisms of action. Am J Med 1994;97:5S-13S. [CrossRef]

14. Ito N, Hirose M. Antioxidants-carcinogenic and chemopreventive properties. Adv Cancer Res 1989;53:247-302. [CrossRef]

15. Gheldof N, Wang XH, Engeseth NJ. Identification and quantification of antioxidant components of honeys from various floral- sources. J Agric Food Chem 2002;50:5870-7. [CrossRef]

16. Kahraman T, Buyukunal SK, Vural A, Altunatmaz SS. Physicochemical properties in honey from different regions of Turkey. Food Chem 2010;123:41-4. [CrossRef]

17. Gunaldi O, Erdogan S, Guclu DG, Tugcu B, Ofluoglu E, Baydin $\mathrm{S}$, et al. "Honey" can prevent epidural fibrosis development after laminectomy: an experimental study. Turk Neurosurg 2014;24:849-54.

18. Mohapatra DP, Thakur V, Brar SK. Antibacterial efficacy of raw and processed honey. Biotechnol Res Int 2011;2011:917505. [CrossRef]

19. Al-Waili NS, Boni NS. Natural honey lowers plasma prostaglandin concentrations in normal individuals. J Med Food 2003;6:129-33.

20. Tonks AJ, Cooper RA, Jones KP, Blair S, Parton J, Tonks A. Honey stimulates inflammatory cytokine production from monocytes. Cytokine 2003;21:242-7. [CrossRef]

21. Almasaudi SB, El-Shitany NA, Abbas AT, Abdel-dayem UA, Ali SS, Al Jaouni SK, et al. Antioxidant, Anti-inflammatory, and Antiulcer Potential of Manuka Honey against Gastric Ulcer in Rats. Oxid Med Cell Longev 2016;2016:3643824. [CrossRef]

22. Doğan A, Kolankaya D. Protective effect of Anzer honey against ethanol-induced increased vascular permeability in the rat stomach. Exp Toxicol Pathol 2005;57:173-8. [CrossRef]

23. Korkmaz A, Kolankaya D. Anzer honey prevents N-ethylmaleimideinduced liver damage in rats. Exp Toxicol Pathol 2009;61:333-7. 